\title{
Patterns of renal disease: A 30-year renal biopsy study at Chris Hani Baragwanath Academic Hospital, Soweto, Johannesburg, South Africa
}

A Vermeulen, ${ }^{1}$ MB BCh, FCP (SA), MMed (Int Med), Cert Nephrology (SA); C N Menezes, ${ }^{2}$ MD, MMed (Int Med), Dip HIV Man (SA), DTM\&H, FCP (SA), Cert ID (SA), PhD; M Mashabane, ${ }^{1}$ MB BCh, FCP (SA), Cert Nephrology (SA); O K Butler, ${ }^{1}$ Med Tech (Microbiology), Clin Tech (Nephrology); P Mosiane, ${ }^{3}$ MB ChB, FC Path (SA) Anat; S Goetsch, ${ }^{4}$ MB ChB, FFPath (SA), MMed (Anat Path), DipRCPath (UK), FRCPath (UK); S Naicker, ${ }^{5} \mathrm{MB}$ ChB, MRCP, FRCP, PhD

\author{
${ }^{1}$ Division of Nephrology, Department of Internal Medicine, Chris Hani Baragwanath Academic Hospital and Faculty of Health Sciences, \\ University of the Witwatersrand, Johannesburg, South Africa \\ ${ }^{2}$ Division of Infectious Diseases, Department of Internal Medicine, Chris Hani Baragwanath Academic Hospital and Faculty of Health Sciences, \\ University of the Witwatersrand, Johannesburg, South Africa \\ ${ }^{3}$ Division of Anatomical Pathology, National Health Laboratory Service and Faculty of Health Sciences, University of the Witwatersrand, \\ Johannesburg, South Africa \\ ${ }^{4}$ Lancet Pathology Laboratory, Johannesburg, South Africa \\ ${ }^{5}$ Department of Internal Medicine, Faculty of Health Sciences, University of the Witwatersrand, Johannesburg, South Africa
}

Corresponding author: A Vermeulen (docaldav@gmail.com)

\begin{abstract}
Background. Data on renal pathology from sub-Saharan Africa are limited.
Objectives. To report on biopsy-confirmed renal pathology over 30 years in Soweto, South Africa (SA).

Methods. Retrospective analysis was conducted of 1848 adult native renal biopsies performed at Chris Hani Baragwanath Academic Hospital between 1 January 1982 and 31 December 2011.

Results. There was an even gender distribution, and $96.4 \%$ of patients were of black ethnicity. The mean (standard deviation) age of patients was 33.5 (12.6) years. The main clinical indications for renal biopsy were nephrotic syndrome (47.7\%), acute kidney injury (19.8\%) and asymptomatic urine abnormalities (8.1\%). Secondary glomerular diseases (SGNs) (49.3\%) occurred more frequently than primary glomerular diseases (PGNs) (39.7\%). SGNs increased during the study period, while PGNs decreased $(p<0.001)$. The most frequent PGNs were focal segmental glomerulosclerosis (FSGS) (29.6\%), membranous glomerulonephritis (25.7\%) and membranoproliferative glomerulonephritis (18.1\%). Lupus nephritis (LN) (31.0\%) was the most frequent SGN, followed by HIV-associated nephropathy (HIVAN) (13.3\%) and malignant hypertension (12.5\%). HIV-positive biopsies constituted 19.7\% of all biopsies, and the proportion increased over time. In HIV-positive patients, the most common diagnoses were HIVAN (32.7\%), HIV immune complex disease (11.8\%) and FSGS (11.3\%).

Conclusions. This study contributes to our knowledge of renal pathology in SA and shows some data that differ from studies in other regions. The increase in SGNs probably reflects the influence of HIV and LN in the study population.
\end{abstract}

S Afr Med J 2019;109(7):486-492. DOI:10.7196/SAMJ.2019.v109i7.13644

The literature suggests that there is a geographical, sociodemographic and temporal variation in histological patterns of renal disease, but data from African countries are fairly limited. ${ }^{[1-3]}$ In South Africa (SA), chronic kidney disease (CKD) more than doubled from 1990 to $2010,{ }^{[4]}$ with the increase mainly attributed to hypertension and glomerular diseases. ${ }^{[5,6]}$

Chris Hani Baragwanath Academic Hospital (CHBAH) serves a predominantly black population of $>3.6$ million people from Soweto (an urban 'township' in Gauteng Province, SA) and the surrounding areas, ${ }^{[7]}$ and is one of the main referral centres for patients with renal disease.

The community served by the hospital has a history of racial segregation, poverty and social inequalities. ${ }^{[8]}$ No recent long-term data for the renal patient population of CHBAH have been published.

\section{Objectives}

To contribute to the knowledge regarding patterns and clinical presentation of renal disease at $\mathrm{CHBAH}$ and compare it with data available for other areas in SA and other countries.

\section{Methods}

A retrospective review was conducted of all renal histopathology reports from 1 January 1982 to 31 December 2011 for patients biopsied in the CHBAH adult renal unit. Renal biopsy remains the most precise method for making a definitive diagnosis of renal disease and predicting the likely clinical course, and guides further investigations and management of patients. ${ }^{[9,10]}$ Our objectives were to describe the histopathological patterns of renal disease and to identify clinical pathological relationships between patient demographics, clinical presentations and histopathological diagnoses. We also compared patterns of renal disease between patients who were HIV-positive and those who were HIV-negative.

Data gathered included the demographic profile (age, gender, ethnicity), results of haematological and urine investigations, indication for biopsy and histopathological diagnosis for each patient. Ethics approval was obtained from the Human Research Ethics Committee of the University of the Witwatersrand (ref. no. M120874).

Native renal biopsy (one in which the patient's own, as opposed to transplanted, kidneys are biopsied) reports of male and female patients 
aged $\geq 12$ years on which the pathologist reviewing the specimen was able to make a definitive pathological diagnosis were included in the analysis. At $\mathrm{CHBAH}$, patients aged $\geq 12$ years are managed by the adult nephrology unit. Biopsy reports on patients aged $<12$ years, renal allograft biopsies and biopsies where the specimen was inadequate for histopathological diagnosis were not included.

Biopsy specimens were processed by pathologists of the National Health Laboratory Service (NHLS), and prior to 2001 by the South African Institute for Medical Research. Light microscopy and immunofluorescence were utilised for all specimens and electron microscopy for some specimens.

Histopathological diagnoses were classified into four categories, adapted from Mesquita et al.: ${ }^{[1]}$ (i) primary glomerular diseases (PGNs); (ii) secondary glomerular diseases (SGNs); (iii) tubulointerstitial diseases (TIDs); and (iv) miscellaneous/other.

Patients were considered to have a PGN if at the time of biopsy the patient had no report of a known systemic disease and had negative serology for hepatitis B and C viruses (HBV and HCV), HIV and syphilis, a negative antistreptolysin $\mathrm{O}$ titre, negative antinuclear antibodies and negative anti-neutrophil cytoplasmic antibodies. Patients with glomerular disease not classified as a PGN were considered to have an SGN.

PGNs were divided into one of nine pathologies using a classification adapted from Polito et al.:[12] (i) minimal-change disease (MCD); (ii) membranous glomerulopathy (MGN); (iii) focal segmental glomerulosclerosis (FSGS); (iv) IgA nephropathy (IgAN); (v) IgM nephropathy; (vi) mesangioproliferative glomerulonephritis; (vii) membranoproliferative glomerulonephritis (MPGN); (viii) crescentic glomerulonephritis; and (ix) proliferative glomerulonephritis. ${ }^{[12]}$

SGNs were subdivided according to aetiology into four categories adapted from Polito et al..$^{[12]}$ and Okpechi et al.: ${ }^{[13]}$ (i) glomerular disease secondary to a systemic disease (SD), including lupus nephritis (LN) and other autoimmune disorders such as rheumatoid arthritis and mixed connective tissue disorder; (ii) glomerular disease secondary to infectious diseases (IDs), including HIV, HBV, HCV, syphilis, post-infectious glomerulonephritis (PIGN) and others; (iii) glomerular disease associated with a metabolic disease or deposits (MD), including diabetic nephropathy (DN), amyloidosis, light-chain deposition disease, glomerular disease with patterned or organised deposits - immunotactoid GN and fibrillary GN; and (iv) glomerular disease secondary to vascular disease (VD), including benign hypertensive nephroangiosclerosis, malignant hypertensive nephroangiosclerosis (MHN), thrombotic microangiopathy, preeclampsia or the HELLP syndrome (haemolysis, elevated liver enzymes, low platelet count), atheroembolic renal disease, systemic sclerosis and pauci-immune crescentic glomerulonephritis.

Diseases classified as TID included interstitial nephritis (IN), acute tubular necrosis (ATN), pyelonephritis and interstitial renal disease secondary to myeloma.

Miscellaneous diseases included unclassified diseases, end-stage kidney disease (ESKD) of unknown aetiology and unclassified glomerulonephritis, hereditary diseases including Alport's nephritis, thin basement membrane disease, oxalate nephropathy and Fabry's disease, tumours, and symptoms suggesting renal disease but with normal/non-remarkable histological findings.

Clinical indications for biopsy were subdivided as follows: $(i)$ acute kidney injury (AKI); (ii) asymptomatic urine abnormalities (AUAs); (iii) CKD; (iv) haematuria; (v) hypertension; (vi) nephrotic syndrome (NS)/nephrotic-range proteinuria; (vii) nephritic syndrome; (viii) nephritic NS; and (ix) unknown.
SPSS 20 statistical software (IBM, USA) was used for statistical analysis. Frequency distributions for demographic data (age, sex and ethnicity), clinical presentations and histopathological diagnosis were calculated and expressed as proportions. Cross-tabulations between the variables of interest were performed and the $\chi^{2}$ test of independence was used to evaluate the potential statistical significance of associations. ${ }^{[14]}$ Where a $\chi^{2}$ value was calculated, a $p$-value $<0.05$ was considered significant.

To identify potential changes in renal disease patterns over a meaningful time frame and to allow comparison with data from similar studies, the 30-year period for which biopsy results were available was divided into three 10 -year periods, namely 1 January 1982 - 31 December 1991, 1 January 1992 - 31 December 2001, and 1 January 2002 - 31 December 2011.

\section{Results}

A total of 1848 histopathology reports were included for analysis. A total of 570 biopsies were performed between 1 January 1982 and 31 December 1991, 377 were performed between 1 January 1992 and 31 December 2001, and 901 were performed between 1 January 2002 and 31 December 2011. With regard to gender distribution, the proportions of females $(50.2 \%, n=928)$ and males $(49.8 \%, n=920)$ in the sample were almost equal, and the mean (standard deviation) age was 33.5 (12.6) years. The majority of patients were black $(96.4 \%, n=1782)$. The frequencies of other ethnic groups were relatively low, with $1.6 \%$ coloured patients $(n=29), 1.4 \%$ white $(n=26)$ and $0.6 \%$ Indian $(n=11)$.

In total, $19.7 \%(n=364)$ of patients were HIV-positive, $4.5 \%(n=83)$ were HBV-positive and 1.5\% $(n=28)$ were HCV-positive. Between 1982 and 1991, only one patient was reported to be HIV-positive; this increased to $5.8 \%$ between 1992 and 2001, and 37.8\% between 2002 and 2011. Of the HIV-positive patients, 17 (4.7\%) were co-infected with HCV and 32 (8.8\%) with HBV. Young adults aged between 20 and 39 years accounted for $64.0 \%$ of HIV-positive patients.

The most frequent indications for renal biopsy were NS/nephroticrange proteinuria (47.7\%), AKI (19.8\%) and AUAs (8.1\%). The majority of HIV-positive patients were biopsied for NS/nephroticrange proteinuria (39.3\%), AKI (38.5\%) and CKD (8.2\%). The frequency of $\mathrm{AKI}$ as an indication for biopsy increased over the study period ( $p<0.001$ ), while NS decreased from the second decade (1992 $2001)$ to the third decade $(2002-2011)(p<0.001)$. NS as an indication for biopsy declined with increasing age, in contrast to AKI, which became a more frequent indication for biopsy with increasing age.

The most frequent histological findings for patients biopsied for NS were FSGS (19.8\%), MGN (19.2\%), LN (12.3\%), MCD (11.0\%), MPGN (10.6\%) and HIV-associated nephropathy (HIVAN) (4.4\%). Among these patients, FSGS occurred most frequently in those aged $<20$ years, while MGN was most frequent in patients aged $>20$ years.

The most frequent findings in HIV-positive individuals with nephrotic-range proteinuria were HIVAN $(27.3 \%, n=39)$, FSGS $(17.5 \%, n=25)$ and MGN (15.4\%, $n=22)$, compared with FSGS (19.5\%, $n=89)$, MGN $(19.5 \%, n=89)$ and LN $(17.1 \%, n=78)$ in HIVnegative individuals.

Of patients biopsied for AKI, 16.9\% had HIVAN, 15.0\% ATN, 9.0\% LN, 8.5\% MHN, 8.5\% IN and 8.2\% FSGS, while the most frequent findings in patients biopsied for AUAs were LN (80.0\%), HIV immune complex disease (HIV-ICD) (4.0\%), normal kidney (3.3\%), IN (2.0\%) and FSGS (2.0\%).

SGNs (including ID, SD, MD and VD) were the most frequent histological findings, being present in a total of 911 biopsies (49.3\%), while PGNs were diagnosed in 734 (39.7\%) of biopsies, TID in 136 (7.4\%) and miscellaneous diseases/other in 67 (3.6\%). 
PGNs decreased significantly over time $(p<0.001)$, while SGNs increased, PGNs accounting for $37.7 \%(n=215)$ of biopsies between 1982 and 1991, 47.5\% ( $n=179)$ between 1992 and 2001, and 57.4\% $(n=517)$ between 2002 and $2011(p<0.001)$. The proportions of PGN during the three 10 -year periods and changes over time are set out in Table 1.

FSGS was the most frequent PGN across all age groups, occurring in the same proportion (40.0\%) as MGN in patients aged $>60$ years. No statistically significant associations between PGNs and the different age groups were found.

Glomerular diseases secondary to IDs followed by SDs were the most frequent causes of SGNs. Of the SGNs, the proportion of ID increased significantly over time $(p<0.001)$ and VD decreased significantly from the first to the second 10 -year period $(p=0.001)$, while the proportion of SD (with $\mathrm{LN}$ as sole contributor) increased significantly over the same period $(p<0.001)$. DN accounted for $6.6 \%$ of SGNs and was present in $3.2 \%(n=60)$ of all biopsies. The proportions of the SGN groups are shown in Table 2, and the eight most frequently occurring SGNs and their changes over time in Table 3.

LN occurred more frequently in females than in males $(89.4 \%$ v. $10.6 \% ; p<0.001$ ), and more frequently in 20 - 39-year-olds than in individuals aged $\geq 40$ years $(p<0.001)$. No statistically significant association between ethnicity and LN was found. The most frequent clinical indications for renal biopsy in patients with LN were AUAs (42.6\%), NS (38.3\%) and AKI (11.7\%). Class 5 LN alone (25.9\%) was the most frequent International Society of Nephrology (ISN)/Renal Pathology Society (RPS) LN class found, and was present in a total of $53.2 \%(n=150)$ of LN biopsies. Class 4 alone accounted for $18.8 \%$ $(n=53)$ of LN biopsies and class 3 alone for 16.7\% $(n=47)$.

The majority of ID-related biopsies were related to HIV, with a dominant diagnosis of HIVAN (32.7\%). The major histological findings in HIV-positive individuals are shown in Fig. 1. Of the HIVpositive individuals, $265(72.8 \%)$ had CD4+ counts recorded (median CD4+ count 195 cells/ $\mu \mathrm{L}$, range $1-1605)$. CD $4+$ counts $\leq 50$ cells $/ \mu \mathrm{L}$ were associated with HIVAN as a diagnosis $(p<0.001)$. The median

Table 1. Proportions of primary glomerular diseases and changes over time

\begin{tabular}{|c|c|c|c|c|c|}
\hline & $\begin{array}{l}1 \text { Jan } 1982-31 \text { Dec } 1991 \\
(N=274), n(\%)\end{array}$ & $\begin{array}{l}1 \text { Jan } 1992-31 \text { Dec } 2001 \\
(N=167), n(\%)\end{array}$ & $\begin{array}{l}1 \text { Jan } 2002-31 \text { Dec } 2011 \\
(N=293), n(\%)\end{array}$ & $\begin{array}{l}1 \text { Jan } 1982 \text { - } 31 \text { Dec } 2011 \\
(N=734), n(\%)\end{array}$ & $p$-value \\
\hline CresGN & $4(1.5)$ & $3(1.8)$ & $2(0.7)$ & $9(1.2)$ & - \\
\hline FSGS & $69(25.2)$ & $40(24.0)$ & $108(36.9)$ & $217(29.6)$ & 0.002 \\
\hline IgAN & $12(4.4)$ & $5(3.0)$ & $9(3.1)$ & $26(3.5)$ & 0.638 \\
\hline $\operatorname{IgMN}$ & $1(0.4)$ & $1(0.6)$ & 0 & $2(0.3)$ & - \\
\hline MCD & $53(19.3)$ & $15(9.0)$ & $37(12.6)$ & $105(14.3)$ & 0.006 \\
\hline MGN & $67(24.5)$ & $50(29.9)$ & $72(24.6)$ & $189(25.7)$ & 0.370 \\
\hline MPGN & $42(15.3)$ & $40(24.0)$ & $51(17.4)$ & $133(18.1)$ & 0.068 \\
\hline MsPGN & $21(7.7)$ & $13(7.8)$ & $14(4.8)$ & $48(6.5)$ & 0.290 \\
\hline ProlifGN & $5(1.8)$ & 0 & 0 & $5(0.7)$ & - \\
\hline
\end{tabular}

Table 2. Proportions of secondary glomerular disease groups

\begin{tabular}{|c|c|c|c|c|}
\hline & $\begin{array}{l}1 \text { Jan } 1982-31 \text { Dec } 1991 \\
(N=215), n(\%)\end{array}$ & $\begin{array}{l}1 \text { Jan } 1992-31 \text { Dec } 2001 \\
(N=179), n(\%)\end{array}$ & $\begin{array}{l}1 \text { Jan } 2002-31 \text { Dec } 2011 \\
(N=517), n(\%)\end{array}$ & $\begin{array}{l}1 \text { Jan } 1982-31 \text { Dec } 2011 \\
(N=911), n(\%)\end{array}$ \\
\hline ID & $50(23.3)$ & $43(24.0)$ & $206(39.8)$ & $299(32.8)$ \\
\hline MD & $26(12.1)$ & $20(11.2)$ & $47(9.1)$ & $93(10.2)$ \\
\hline SD & $46(21.4)$ & 87 (48.6) & $149(28.8)$ & $282(31.0)$ \\
\hline VD & $93(43.3)$ & $29(16.2)$ & $115(22.2)$ & $237(26.0)$ \\
\hline
\end{tabular}

Table 3. Most frequent secondary glomerular diseases for each 10 -year period and the total study period

\begin{tabular}{|c|c|c|c|c|c|}
\hline & $\begin{array}{l}1 \text { Jan } 1982 \text { - } 31 \text { Dec } 1991 \\
(N=215), n(\%)\end{array}$ & $\begin{array}{l}1 \text { Jan } 1992-31 \text { Dec } 2001 \\
(N=179), n(\%)\end{array}$ & $\begin{array}{l}1 \text { Jan } 2002-31 \text { Dec } 2011 \\
(N=517), n(\%)\end{array}$ & $\begin{array}{l}1 \text { Jan } 1982-31 \text { Dec } 2011 \\
(N=911), n(\%)\end{array}$ & $p$-value \\
\hline AMY & $16(7.4)$ & $4(2.2)$ & $8(1.5)$ & $28(3.1)$ & $<0.001$ \\
\hline $\mathrm{BHN}$ & $48(22.3)$ & $4(2.2)$ & $36(7.0)$ & $88(9.7)$ & $<0.001$ \\
\hline $\mathrm{DN}$ & $10(4.7)$ & $16(8.9)$ & $34(6.6)$ & $60(6.6)$ & 0.232 \\
\hline HIVAN & $1(0.5)$ & $12(6.7)$ & $108(20.9)$ & $121(13.3)$ & $<0.001$ \\
\hline HIV-ICD & 0 & 0 & $43(8.3)$ & $43(4.7)$ & $<0.001$ \\
\hline $\mathrm{LN}$ & $46(21.4)$ & $87(48.6)$ & $149(28.8)$ & $282(31.0)$ & $<0.001$ \\
\hline $\mathrm{MHN}$ & $41(19.1)$ & $13(7.3)$ & $60(11.6)$ & $114(12.5)$ & 0.001 \\
\hline PIGN & $36(16.7)$ & $24(13.4)$ & $23(4.4)$ & $83(9.1)$ & $<0.001$ \\
\hline
\end{tabular}


creatinine level for HIV-positive patients was $316 \mu \mathrm{mol} / \mathrm{L}$ and the median protein-creatinine ratio (PCR) $0.61 \mathrm{~g} / \mathrm{mmol}$, which is in the nephrotic range of proteinuria. The median CD4+ count, creatinine level and PCR for different histopathological diagnoses in HIVpositive patients are shown in Table 4 .

In patients who were co-infected with HBV and HIV, the most prevalent findings were HIVAN $(25.0 \%, n=8)$ followed by FSGS and MGN (15.6\% $(n=5)$ each). In patients with HCV and HIV co-infection, the most prevalent findings were HIVAN $(29.4 \%, n=5)$ and HIV-ICD $(17.6 \%, n=3)$, followed by FSGS and MCD $(11.8 \%$ $(n=2)$ each).

PIGN was present in 83 patients (4.5\%). The frequency of PIGN as a cause of SGN decreased significantly during the study period $(p<0.001)$. Most patients with PIGN were of black ethnicity $(96.4 \%$, $n=80$ ), while $65.1 \%$ of patients with PIGN were aged $<40$ years.

\section{Discussion}

Studies from SA relating to histopathological findings in renal disease are from different geographical areas, and ethnic distributions in the study populations vary. We reviewed a sample in Gauteng Province that largely consisted of patients of black ethnicity (96.4\%), while other studies were of predominantly mixed-race patients $(53.7 \%)$ in

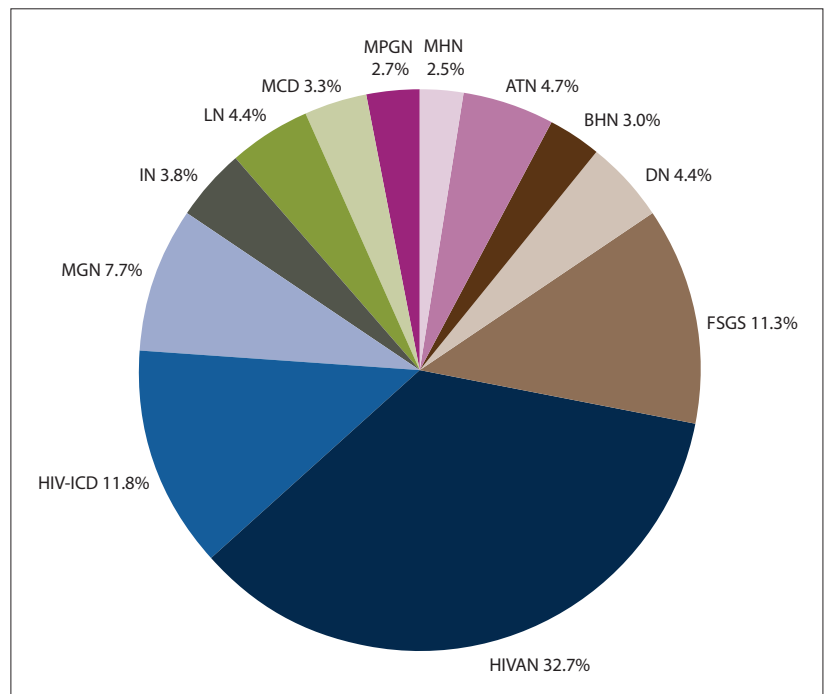

Fig. 1. Histopathological findings in HIV-positive individuals. $(A T N=$ acute tubular necrosis; $B H N=$ benign hypertensive nephroangiosclerosis; $D N=$ diabetic nephropathy; FSGS = focal segmental glomerulosclerosis; HIVAN = HIV-associated nephropathy; HIV-ICD = HIV immune complex disease; $M G N=$ membranous glomerulopathy; IN = interstitial nephritis; $L N=$ lupus nephritis; $M C D=$ minimal-change disease; $M P G N=$ membranoproliferative glomerulonephritis; $M H N=$ malignant hypertensive nephroangiosclerosis.)
Cape Town, Western Cape Province, ${ }^{[13]}$ and 57.2\% black and 35.9\% white patients in Bloemfontein, Free State Province. ${ }^{[15]}$ Our study adds significantly to the knowledge regarding the patterns of renal disease in SA and sub-Saharan Africa as a whole, where the majority of patients are of black ethnicity.

As can be seen in Table 5, we found indications for biopsy similar to those in published studies from Africa, ${ }^{[13,15-19]}$ the Middle East, ${ }^{[20,21]}$ Asia, ${ }^{[22-26]}$ South America ${ }^{[12,27]}$ and parts of Europe, ${ }^{[28,29]}$ with the most frequent indication for biopsy being nephrotic-range proteinuria (47.7\%). However, studies in Belgium, ${ }^{[11]}$ Finland $^{[30]}$ and Italy ${ }^{[31]}$ reported AUAs as the most frequent indication for biopsy, possibly because their well-resourced healthcare systems enable early detection of asymptomatic disease. With that said, after AKI (19.8\%) as the second most prevalent indication for biopsy, AUAs were in fact the third most prevalent indication in the present study, accounting for $8.1 \%$ of biopsies. This probably reflects the active screening for renal disease in LN patients at our facility, as most patients biopsied for AUA had LN (80.0\%). CKD was the most frequent indication in France ${ }^{[32]}$ and chronic nephritic syndrome in Japan, ${ }^{[33]}$ probably owing to the high prevalence of IgAN in that part of the world.

The three most frequent histological findings in patients with NS in our study were FSGS (19.8\%), MGN (19.2\%) and LN (12.3\%). However, when evaluating nephrotic-range proteinuria and NS in 294 black patients, Okpechi et al. ${ }^{[34]}$ in Cape Town identified the most frequent causes of NS as HIVAN (25.2\%), MPGN (7.8\%) and LN (7.8\%), while Seedat ${ }^{[35]}$ in Durban, SA, reported MPGN to be the most frequent cause of NS in black patients (47.0\%), followed by MGN (25.0\%).

We found that SGNs (49.3\%) occurred more frequently than PGNs (39.7\%). Together with the findings of Okpechi et al. ${ }^{[13]}$ in Cape Town and Mesquita et al. ${ }^{[11]}$ in Belgium, this contrasts with the majority of studies, which report PGNs as occurring more frequently.

The most frequent PGNs in the present study were FSGS (29.6\%), MGN (25.7\%) and MPGN (18.1\%), which is in keeping with other studies from Africa ${ }^{[15,16,18,19,36]}$ that report FSGS as the most frequent PGN. The high frequency of FSGS in our study sample may be explained by a possible genetic predisposition in the predominantly black patient population, similar to that shown in African Americans, where the presence of a single $A P O L 1$ risk allele (G1 or G2) is associated with a 17-fold higher odds for FSGS and a 29-fold higher odds for HIVAN. ${ }^{[37]}$ Preliminary data from SA show that individuals carrying any combination of two APOL1 risk alleles have 89-fold higher odds of developing HIVAN and 6.3 higher odds for primary FSGS; population allele frequencies were $7.3 \%$ for G1 and $11.1 \%$ for G2. ${ }^{[38]}$ Further research is required to adequately explore this hypothesis and to clarify the reasons for the higher frequency of FSGS.

IgAN accounted for only $3.5 \%$ of PGN in the present study, while IgAN is reported as the most frequent PGN in most of Europe, ${ }^{[29-32]}$

Table 4. CD4+ counts, serum creatinine levels and PCR for various histopathological diagnoses in HIV-positive patients

\begin{tabular}{|c|c|c|c|}
\hline Histopathological diagnosis & $\begin{array}{l}\text { CD4+ count }(\text { cells } / \mu \mathrm{L}) \text {, } \\
\text { median }(\mathrm{IQR})\end{array}$ & $\begin{array}{l}\text { Creatinine }(\mu \mathrm{mol} / \mathrm{L}) \text {, } \\
\text { median }(\mathrm{IQR})\end{array}$ & $\begin{array}{l}\text { PCR (g/mmol), } \\
\text { median (IQR) }\end{array}$ \\
\hline HIVAN & $92(28-196)$ & $539(279-799)$ & $0.92(0.37-1.44)$ \\
\hline HIV-ICD & $198(85-297)$ & $141(76-435)$ & $0.31(0.06-0.70)$ \\
\hline FSGS & $434(174-566)$ & $104(80-331)$ & $0.83(0.40-1.38)$ \\
\hline MGN & $360(197-491)$ & $89(74-220)$ & $0.78(0.46-0.99)$ \\
\hline MCD & $165(77-226)$ & $119(76-175)$ & $0.83(0.26-1.51)$ \\
\hline MPGN & $380(316-435)$ & $207(76-333)$ & $0.99(0.28-1.20)$ \\
\hline
\end{tabular}


Table 5. Comparative summary of histopathology findings from similar studies

\begin{tabular}{|c|c|c|c|c|c|c|}
\hline Country & Year & Author & $\begin{array}{l}\text { Most frequent } \\
\text { indication (\%) }\end{array}$ & $\begin{array}{l}\text { Most frequent } \\
\text { group (\%) }\end{array}$ & $\begin{array}{l}\text { Most frequent } \\
\text { PGN (\%) }\end{array}$ & $\begin{array}{l}\text { Most frequent } \\
\text { SGN (\%) }\end{array}$ \\
\hline \multicolumn{7}{|l|}{ Africa } \\
\hline SA, CHBAH (present study) & & Vermeulen et al. & NS (47.7) & SGN (49.3) & FSGS (29.6) & LN (31) \\
\hline $\mathrm{SA}, \mathrm{CPT}$ & 2011 & Okpechi et al. ${ }^{[13]}$ & NS (52.5) & SGN (49.0) & MPGN (20.4) & LN (39) \\
\hline SA, Bloemfontein & 2010 & Jansen van Rensburg et al. ${ }^{[15]}$ & NS & - & FSGS & - \\
\hline Egypt & 2000 & Barsoum and Francis ${ }^{[16]}$ & NS (31.9) & - & FSGS (22.6) & - \\
\hline Morocco & 2012 & Aatif et al..$^{[17]}$ & NS (60.3) & PGN (52) & $\operatorname{MCD}(26)$ & LN (45) \\
\hline Oman & 2013 & Dawood et al..$^{[36]}$ & - & SGN & FSGS & $\mathrm{LN}(36.1)$ \\
\hline Senegal & 2003 & Abdou et al. ${ }^{[18]}$ & NS (67) & PGN (69.5) & FSGS (47) & $\mathrm{LN}(55.5)$ \\
\hline Sudan & 2013 & Nadium et al..$^{[19]}$ & NS (46.5) & PGN (85.5) & FSGS (29.6) & - \\
\hline \multicolumn{7}{|l|}{ Middle East } \\
\hline Iran & 2010 & Ossareh et al. ${ }^{[20]}$ & NS (57.4) & PGN (74.8) & MGN (35.8) & $\mathrm{LN}(64.3)$ \\
\hline Jordan & 2008 & Wahbeh et al..$^{[21]}$ & NS (51.6) & PGN (59.4) & FSGS & $\mathrm{LN}$ \\
\hline \multicolumn{7}{|l|}{ Europe } \\
\hline Belgium & 2011 & Mesquita et al. ${ }^{[11]}$ & AUA (53.5) & SGN (39.9) & FSGS (30.3) & IMGN (32.3) \\
\hline Finland & 2008 & Wirta et al. ${ }^{[30]}$ & AUA (38.7) & PGN & $\operatorname{IgAN}(34.9)$ & - \\
\hline France & 2004 & Simon et al. ${ }^{[32]}$ & CKD (36) & PGN & $\operatorname{IgAN}(73.4)$ & - \\
\hline Italy & 2004 & Gesualdo et al. ${ }^{[31]}$ & AUA & PGN (64.3) & $\operatorname{IgAN}(34.5)$ & IMGN \\
\hline Serbia & 2009 & Naumovic et al. ${ }^{[28]}$ & NS (53.6) & PGN (64.2) & $\begin{array}{l}\text { MsPGN, non- } \\
\text { IgA }(25.1)\end{array}$ & LN (75.6) \\
\hline Spain & 2002 & Rivera et al. ${ }^{[29]}$ & NS (35.2) & PGN & IgAN (17.2) & LN \\
\hline \multicolumn{7}{|l|}{ Asia } \\
\hline China & 2012 & Hsiao et al. ${ }^{[22]}$ & NS (52) & PGN (55) & MGN (31.7) & $\mathrm{LN}(53.2)$ \\
\hline East India & 2013 & Golay et al. ${ }^{[23]}$ & NS (61.6) & PGN (79.13) & FSGS & LN (73.38) \\
\hline South India & 2011 & Das et al. ${ }^{[24]}$ & NS (49) & PGN (69.1) & $\operatorname{MCD}(21.8)$ & LN (80.1) \\
\hline Japan & 2011 & Sugiyama et al..$^{[33]}$ & CNS (48.2) & PGN & $\operatorname{IgAN}(27.6)$ & $\mathrm{DN}$ \\
\hline Korea & 2009 & Chang et al. ${ }^{[39]}$ & - & PGN & $\operatorname{IgAN}(28.3)$ & LN (74) \\
\hline Northern China & 2009 & Zhou et al..$^{[25]}$ & NS & PGN (63.3) & IgAN (54.5) & - \\
\hline Pakistan & 2011 & Mubarak et al. ${ }^{[26]}$ & NS (49.9) & PGN (73) & FSGS (29) & $\mathrm{LN}(44.1)$ \\
\hline \multicolumn{7}{|l|}{ Americas } \\
\hline Brazil & 2010 & Polito et al. ${ }^{[12]}$ & NS (39) & PGN (51) & FSGS (24.6) & LN (45.5) \\
\hline Colombia & 2009 & Arias et al. ${ }^{[27]}$ & NS & PGN (76.2) & FSGS (37.7) & LN (90.9) \\
\hline USA, Minnesota & 2006 & Swaminathan et al. ${ }^{[40]}$ & - & - & $\operatorname{IgAN}(22)$ & - \\
\hline Australia & 2001 & Briganti et al. ${ }^{[41]}$ & - & - & $\operatorname{IgAN}(34.1)$ & - \\
\hline
\end{tabular}

parts of Asia, ${ }^{[25,33,39]}$ the USA (white Americans) ${ }^{[40]}$ and Australia. ${ }^{[41]}$ It is possible that IgAN may be under-represented in our study because of the ethnic distribution of the study sample and because patients with isolated haematuria are not often subjected to renal biopsy.

The present study found, as in most other parts of the world including SA, ${ }^{[12,13,15,17,19-24,26-29,36,39]}$ that LN (31.0\%) was the most frequent SGN, followed in our study by HIVAN (13.3\%) and MHN (12.5\%). The most frequent ISN/RPS histological subtypes of LN in our study, class V (25.9\%) followed by class IV (18.8\%), differ from Okpechi et al.'s ${ }^{[42]}$ finding that subtypes class III and IV $(20.7 \%$ each) occurred most frequently in their Cape Town sample. The frequencies of class I and class II LN may be under-represented in general, as most patients with these two classes of LN are not routinely biopsied owing to inactive urine sediment, proteinuria $<1 \mathrm{~g} / \mathrm{d}$ and normal kidney function. ${ }^{[43]}$

The first patient in the present study to be reported as HIVpositive was a patient with HIVAN in 1989, 5 years prior to the first published case of HIVAN in SA, reported by Bates et al. ${ }^{[44]}$ in 1994. The proportion of HIV-positive patients in our study increased over the study period $(p<0.001)$, and with $37.8 \%$ HIV-positive biopsies between 1 January 2002 and 31 December 2011, the prevalence was higher than the highest reported antenatal HIV seroprevalence in Gauteng for the same period, which was $33.1 \%$ in $2004 .{ }^{[45]}$

Similar to our study, histological patterns in HIV-positive individuals from other parts of SA as well as from the USA indicate HIVAN to be the most frequent histopathological finding. The most frequent findings in HIV-positive individuals in the present study were HIVAN (32.7\%), HIV-ICD (11.8\%) and FSGS (11.3\%). HIVAN accounted for $55.3 \%$ of biopsies at Groote Schuur Hospital in Cape Town $^{[46]}$ and $83 \%$ in Durban, ${ }^{[4]}$ followed by ATN $(8.0 \%)$ and ESKD (7.2\%) in Cape Town and IN (10.0\%) and MPGN (7.0\%) in Durban. Berliner et al. ${ }^{[48]}$ in Baltimore, USA, reported HIVAN (35\%), noncollapsing FSGS (22\%) and acute interstitial nephritis (7.9\%) as their most frequent findings. The differences in HIVAN prevalence between the SA studies are not surprising in themselves - as pointed out by Koech et al., ${ }^{[49]}$ studies show great variability in the prevalence of HIVAN in HIV-positive populations. This variability is poorly understood but could be influenced by various factors, including, 
as pointed out by Wearne et al. ${ }^{[50]}$ differing approaches to the classification of HIVAN between studies, differences in duration of HIV infection, or genetic differences between populations. Regardless of the apparent variability, HIVAN does appear to be the most prevalent finding in HIV-positive biopsies and has been increasing.

The statistically significant increase in SGNs $(p<0.001)$ and decrease in PGNs $(p<0.001)$ in the present study can probably be explained by the increase in ID $(p<0.001)$ during the study period, which in turn is likely to be linked to the increased prevalence of HIV-related diseases during the last decade between 2002 and 2011.

Non-SA studies reporting on differences in the frequency of agerelated PGN report the most frequent PGNs in young adults to be either IgAN or FSGS, and in the elderly, MGN..$^{[3]}$ The present study found FSGS to be the most frequent PGN across all age groups except for patients aged 20 - 39 years and those aged $\geq 60$, among whom FSGS and MGN occurred at the same frequency. Similar to the present study, MGN was also reported to be the most frequent PGN in the elderly in France, ${ }^{[31]}$ Ireland, ${ }^{[51]}$ Brazil ${ }^{[12]}$ and Cape Town. ${ }^{[13]}$ Okpechi et al. ${ }^{[13]}$ however, found MPGN to be the most frequent PGN in patients aged $<60$.

\section{Study limitations}

The retrospective nature of the present study leads to some limitations. Inconsistencies in the recording and reporting of data over the 30-year period as well as records that might have been misplaced make it possible that some biopsies or associated data were not included in the data set. However, every effort was made to locate all relevant records and data, including sourcing of archival patient records. Some renal diseases could be under-represented in the data because affected patients are not routinely biopsied; $\mathrm{DN}$ and isolated microscopic haematuria that may be due to IgAN are two such conditions. Contraindications to renal biopsy in patients who present with advanced renal failure may result in under-representation of the true frequency of various pathologies, including HIVAN and HIV-ICD. The data may also be skewed by the high referral rate for biopsies of systemic lupus erythematosus patients by the Division of Rheumatology at CHBAH. As some patients are likely to use the private health sector or simply prefer to make use of other hospitals, the sample of biopsies in this study may not fully represent the complete picture of renal disease for patients in the Soweto area. Generalisation from our results should be made cautiously.

\section{Conclusions}

Overall, the present study contributes to the literature on patterns of renal disease in SA as well as sub-Saharan Africa, and when compared with existing studies shows variation in patterns of renal disease seen in diverse ethnic populations, various geographical areas and differing socioeconomic groups worldwide. The apparent impact of HIV on renal disease epidemiology is noteworthy. Our study describes the patterns of renal disease in a predominantly black African population and may aid as a guide to possible pathological diagnosis in black patients with contraindications to or no access to renal biopsy. The study points to the potential value of research regarding genetic profiling of the SA renal disease population to determine the actual prevalence of the APOL1 gene. Further prospective research on patterns of renal disease and studies linking outcomes in this area are also recommended.

Declaration. This study was done in fulfilment of the requirements of AV's MMed in Internal Medicine with the University of the Witwatersrand, Johannesburg.

\section{Acknowledgements. None.}

Author contributions. AV, CNM and MM conceived the study. AV and OKB collected the data. AV prepared the manuscript. PM and SG assisted with access to the NHLS data. CNM, MM and SN were responsible for critical revision of the manuscript.

Funding. None.

Conflicts of interest. None.

1. Pesce F, Schena FP. Worldwide distribution of glomerular diseases: The role of renal biopsy registries. Nephrol Dial Transplant 2010;25(2):334-336. https://doi.org/10.1093/ndt/gfp620

2. Sliem HA, Tawfik GA, Atwa M, Keshawy MM. The histopathological profile of kidney diseases in a Sliem HA, Tawfik GA, Atwa M, Keshawy MM. The histopathological profile of kidney diseases in
single center in Egypt: An overview of 14 years of experience. J Clin Diagn Res 2011:5(2):295-300.

3. Okpechi I, Duffield M, Swanepoel C. Primary glomerular diseases: Variations in disease types seen in Africa and Europe. Port J Nephrol Hypertens 2012;26(1):25-31.

4. Mayosi BM, Benatar SR. Health and health care in South Africa - 20 years after Mandela. N Engl J Med 2014;371:1344-1353. https://doi.org/10.1056/NEJMsr1405012

Naicker S. End-stage renal disease in sub-Saharan Africa. Kidney Int Suppl 2013;3(2):161-163. https:// doi.org/10.1038/kisup.2013.4

Gold CH, Isaacson C, Levin J. The pathological basis of end-stage renal disease in blacks. S Afr Med J 1982;61:263-265.

7. Gauteng Department of Health. Budget Statement 2, 2009/10, p. 9. http://www.treasury.gov.za/ documents/provincial\%20budget/2009/Budget\%20Statements/GT/GP\%20-\%20Vote\%2004\%20-\%20 Health.pdf (accessed 22 May 2019).

8. Horwitz S. Baragwanath Hospital, Soweto. A History of Medical Care 1941 - 1990. Johannesburg: Wits University Press, 2013:27-55. https://doi.org/10.18772/12013097472.8

9. Schena FP, Gesualdo L. Satellite symposium: Renal biopsy registries. Kidney Int 2004;66(3):889. Schena FP, Gesualdo L. Satellite symposium:

Thewie AJ. Handbook of Renal Biopsy Pathology. 2nd ed. New York: Springer Science \& Business . Howie AJ. Handbook of Renal Biopsy Pathology. 2nd ed. New
Media, 2008:1-3. https://doi.org/10.1007/978-0-387-74605-0

11. Mesquita M, Fosso C, Bakoto Sol E, et al. Renal biopsy findings in Belgium: A retrospective single center analysis. Acta Clin Belg 2011;66(2):104-109.

12. Polito MG, de Moura LAR, Kirsztajn GM. An overview on frequency of renal biopsy diagnosis in Brazil: Clinical and pathological patterns based on 9617 native kidney biopsies. Nephrol Dial Transpl 2010;25(2):490-496. https://doi.org/10.1093/ndt/gfp355

13. Okpechi I, Swanepoel C, Duffield M, et al. Patterns of renal disease in Cape Town, South Africa: A 10year review of a single centre renal biopsy database. Nephrol Dial Transplant 2011;269(6):1853-1861. https://doi.org/10.1093/ndt/gfq655

14. Plichta SB, Kelvin E. Munro's Statistical Methods for Healthcare Research. 6th ed. Philadelphia: Wolters Kluwer Health, 2013:289-316.

15. Jansen van Rensburg BW, van Staden AM, Rossouw GJ, Joubert G. The profile of adult nephrology patients admitted to the Renal Unit of the Universitas Tertiary Hospital in Bloemfontein, South Africa, from 1997 to 2006. Nephrol Dial Transplant 2010;25(3):820-825. https://doi.org/10.1093/ndt/gfp535

6. Barsoum RS, Francis MR. Spectrum of glomerulonephritis in Egypt. Saudi J Kidney Dis Transpl Barsoum RS, Francis

17. Aatif T, Maoujoud O, Montasser DI, Benyahia M, Oualim Z. Glomerular diseases in the Military Hospital of Morocco: Review of a single centre renal biopsy database on adults. Indian J Nephrol 2012;22(4):257-263. https://doi.org/10.4103/0971-4065.101244

18. Abdou N, Boucar D, Fary KAEH, et al. Histopathological profiles of nephropathies in Senegal. Saudi J Kidney Dis Transpl 2003;14(2):212-214

19. Nadium WK, Abdelwahab HH, Ibrahim MA, Shigidi MM. Histological pattern of primary glomerular disease among adult Sudanese patients: A single center experience. Indian J Nephrol 2013;23(3):176179. https://doi.org/10.4103/0971-4065.111838

20. Ossareh S, Asgari M, Abdi E, et al. Renal biopsy findings in Iran: Case series report from a referral kidney center. Int Urol Nephrol 2010;42(4):1031-1040. https://doi.org/10.1007/s1 1255-009-9684-0

21. Wahbeh AM, Ewais MH, Elsharif ME. Spectrum of glomerulonephritis in adult Jordanians at Jordan University Hospital. Saudi J Kidney Dis Transpl 2008;19(6):997-1000.

22. Hsiao K, Lian J, Wu S, et al. Ten-year registry of native kidney biopsy from a single center in Taichung. Acta Nephrologica 2012;26(2):68-73.

23. Golay V, Trivedi M, Abraham A, Roychowdhary A, Pandey R. The spectrum of glomerular diseases in a single center: A clinicopathological correlation. Indian J Nephrol 2013;23(3):168-175. https://doi. org/10.4103/0971-4065.111833

24. Das U, Dakshinamurty KV, Prayaga A. Pattern of biopsy-proven renal disease in a single center of south India: 19 years experience. Indian J Nephrol 2011;21(4):250-257. https://doi.org/10.4103/09714065.85482

25. Zhou F, Zhao M, Zou W, Liu G, Wang H. The changing spectrum of primary glomerular diseases within 15 years: A survey of 3331 patients in a single Chinese centre. Nephrol Dial Transplant 2009;24(3):870-876. https://doi.org/10.1093/ndt/gfn554

26. Mubarak M, Kazi JI, Naqvi R, et al. Pattern of renal diseases observed in native renal biopsies in adults in a single centre in Pakistan. Nephrology 2011;16(1):87-92. https://doi.org/10.1111/j.14401797.2010.01410.x

27. Arias LF, Henao J, Giraldo RD, Carvajal N, Rodelo J, Arbeláez M. Glomerular diseases in a Hispanic population: Review of a regional renal biopsy database. Sao Paulo Med J 2009;127(3):140-144. https:// doi.org/10.1590/S1516-31802009000300006

28. Naumovic R, Pavlovic S, Stojkovic D, Basta-Jovanovic G, Nesic V. Renal biopsy registry from a single centre in Serbia: 20 years of experience. Nephrol Dial Transplant 2009;24(3):877-888. https://doi.
colic centre in Serbia: 20 years

29. Rivera F, López-Gómez JM, Pérez-García R. Frequency of renal pathology in Spain 1994 - 1999. . Rivera F, López-Gómez JM, Pérez-García R. Frequency of renal pathology in Spai
Nephrol Dial Transplant 2002;17(9):1594-1602. https://doi.org/10.1093/ndt/17.9.1594

Nephrol Dial Transplant 2002;17(9):1594-1602. https://doi.org/10.1093/ndt/17.9.1594 . Wirta O, Mustonen J, Helin H, Pasternack A. Incidence of biopsy-proven g
Dial Transplant 2008;23(1):193-200. https://doi.org/10.1093/ndt/gfm564

31. Gesualdo L, Palma AMD, Morrone LF, Strippoli GF, Schena FP. The Italian experience of the national registry of renal biopsies. Kidney Int 2004;66(3):890-894. https://doi.org/10.1111/j.15231755.2004.00831.x

32. Simon P, Ramee MP, Boulahrouz R, et al. Epidemiologic data of primary glomerular diseases in western France. Kidney Int 2004;66(3):905-908. https://doi.org/10.1111/j.1523-1755.2004.00834.x

33. Sugiyama H, Yokoyama H, Sato H, et al. Japan Renal Biopsy Registry: The first nationwide, web-based, and prospective registry system of renal biopsies in Japan. Clin Exp Nephrol 2011;15(4):493-503. https://doi.org/10.1007/s10157-011-0430-4

34. Okpechi I, Rayner BL, Swanepoel CR. Nephrotic syndrome in adult black South Africans: HIVassociated nephropathy as the main culprit. J Natl Med Assoc 2010;102(12):1193-1197. https://doi. org/10.1016/S0027-9684(15)30774-4 
35. Seedat YK. Glomerulonephritis in South Africa. Nephron 1992;60(3):257-259. https://doi. org $/ 10.1159 / 000186762$

36. Dawood AR, Al Shaaili K, Al Bulushi Y, Al Dhahli A, Date A. The spectrum of glomerular diseases on renal biopsy: Data from a single tertiary center in Oman. Oman Med J 2013;28(3):213-215. https:// doi.org/10.5001/omj.2013.58

37. Kopp JB, Nelson GW, Sampath K, et al. APOL1 genetic variants in focal segmental glomerulosclerosis and HIV-associated nephropathy. J Am Soc Nephrol 2011;22(11):2129-2137. https://doi.org/10.1681/ ASN.2011040388

38. Kasembeli A, Duarte R, Ramsay M, et al. APOL1 risk variants show the highest reported association with HIV-associated nephropathy (HIVAN) in black South Africans. J Am Soc Nephrol 2015;26(11):2882-2890. https://doi.org/10.1681/ASN.2014050469

39. Chang JH, Kim DK, Kim HW, et al. Changing prevalence of glomerular diseases in Korean adults: A review of 20 years of experience. Nephrol Dial Transplant 2009;24(8):2406-2410. https://doi. org/10.1093/ndt/gfp091

40. Swaminathan S, Leung N, Lager DJ, et al. Changing incidence of glomerular disease in Olmsted County, Minnesota: A 30-year renal biopsy study. Clin J Am Soc Nephrol 2006;1(3):483-487. https:// doi.org/10.2215/CJN.0071080

41. Briganti EM, Dowling J, Finlay M, et al. The incidence of biopsy-proven glomerulonephritis Australia. Nephrol Dial Transplant 2001;16(7):1364-1367. https://doi.org/10.1093/ndt/16.7.1364

42. Okpechi IG, Swanepoel CR, Tiffin N, Duffield M, Rayner BL. Clinicopathological insights into lupus nephritis in South Africans: A study of 251 patients. Lupus 2012;21(9):1017-1024. https://doi. org/10.1177/0961203312441981

43. Appel GB, Radhakrishnan J, D’Agati V. Secondary glomerular disease. In: Taal MW, Yu ASL, Chertow GM, Brenner BM, Marsden PA, Skorecki K, eds. Brenner and Rector's The Kidney. 9th ed. Philadelphia: Elsevier, 2012:1192-1277.
44. Bates WD, Muller N, van de Wal BW, Jacobs JC. HIV-associated nephropathy - an initial presentation in an HIV-positive patient. S Afr Med J 1994;84:223-224.

45. Health Systems Trust. HIV prevalence (\%) (antenatal). Health Statistics. 2013. http://www.healthlink org.za/healthstats/13/data (accessed 9 September 2013).
or.

46. Swanepoel CR, Okpechi IG. HIV and renal disease in Africa: The journey so far and future directions. Port J Nephrol Hypert 2011;25(1):11-15.

47. Han TM, Naicker S, Ramdial PK, Assounga AG. A cross-sectional study of HIV-seropositive patients with varying degrees of proteinuria in South Africa. Kidney Int 2006;69(12):2243-2250. https://doi with varying degrees of
org $/ 10.1038 /$ s..ki.5000339

8. Berliner AR, Fine DM, Lucas GM, et al. Observations on a cohort of HIV-infected patients undergoin native renal biopsy. Am J Nephrol 2008;28(3):478-486. https://doi.org/10.1159/000112851

4. Koech MK, Owiti MOG, Owino-Ongor WD, et al. Absence of HIV-associated nephropathy among antiretroviral naive adults with persistent albuminuria in Western Kenya. Kidney Int Rep 2017;2(2):159-164. https://doi.org/10.1016/j.ekir.2016.11.007

50. Wearne N, Swanepoel CR, Boulle A, Duffield MS, Rayner BL. The spectrum of renal histologies seen in HIV with outcomes, prognostic indicators and clinical correlations. Nephrol Dial Transplant 2012;27(11):4109-4118. https://doi.org/10.1093/ndt/gfr702

51. Brown CM, Scheven L, O'Kelly P, Dorman AM, Walsh J. Renal histology in the elderly: Indications and outcomes. J Nephrol 2012;25(2):240-244. https://doi.org/10.5301/JN.2011.8447

Accepted 7 January 2019 